\title{
Role of Touch Perception and Audio Aids as Patient Education and Motivation Tools in Adjunct to the Use of Manual and Electronic Toothbrushes in Visually Impaired Individuals: A Cross over Study
}

\author{
Dr. Akshita Solanki ${ }^{1}$, Dr. Ashlesha A. Pabale ${ }^{2}$, Dr. Rashmi Hegde ${ }^{3}$, \\ Dr. Sanjay Jain ${ }^{3}$, Dr. Sangeeta Muglikar ${ }^{4}$ \\ 1,2,3,4 (Department of Periodontology, M A Rangoonwala College of Dental Science and Research \\ Centre/Maharashtra University of Health Science India)
}

\begin{abstract}
:
Background: Dental treatment is the greatest unattended health need of physically/mentally disabled individuals. However, oral hygiene can be improved significantly by effectual daily brushing and self-training workshops. With this background, an effort was made to compare the efficacy of manual and electronic toothbrushes in plaque control of visually impaired individuals. A comparison of efficacy of touch perception and audio aids as patient education and motivation tools and a preference of toothbrush from blind individuals was obtained.

Materials and methods: A cross over clinical study of 2 months duration which included 30 individuals consisting of 2 phases of 1 month for each of the 2 groups. At baseline, after completion of oral prophylaxis, the subjects were asked to listen to audio aids and were asked to read oral hygiene instructions printed on Braille pamphlets. Subjects were taught manually to brush by manual and electronic toothbrushes. Group A were given manual toothbrushes and group B were given electronic toothbrushes followed by recording Oral Hygiene Index, Gingival Index and Plaque Indexscores.The groups were reassessed after a period of 4 weeks for the same parameters. A crossover was done between group A and group B. After 4 weeks, the subjects were evaluated for the above parameters.
\end{abstract}

Result: OHI, GI and PI in intra-group comparison improved significantly before and after crossover $(P-$ value $<0.05$ for all).In inter-group comparison OHI, GI and PI values for manual crossed over to electronic group where higher, but difference did not reach statistical significance ( $P$-value $>0.05$ for all)

Keyword: Audio Aids, Electronic tooth brush, Braille, Manual toothbrush, Crossover

\section{Introduction}

Dental plaque is the primary etiological factor in periodontal diseases ${ }^{1}$.The elimination and control of plaque formation helps to prevent gingivitis and reduce the severity of periodontitis ${ }^{2}$. However in case of visually impaired individuals there can be a difficulty in maintaining the oral hygiene. This can have a negative effect on oral health of these individuals ${ }^{3,4}$. Any type of visual impairment may impact the oral health, because of the physical, social and informational barriers related to their impairment ${ }^{5}$. Visually impaired individuals have an increased incidence of periodontal disease due to increased accumulation of calculus and debris when compared to those who lack visual impairment ${ }^{3,6}$. They respond to good verbal instructions and tactile aids thus improving the tooth brushing technique ${ }^{7,8}$.

Adequate oral hygiene instructions can have a positive impact on oral hygiene and periodontal status of visually impaired individuals ${ }^{7,8}$. It has been proved that lack of physical dexterity makes the use of electronic toothbrush more effective when compared to manual toothbrush as in case of physically handicapped individuals and mentally challenged individuals ${ }^{9-12}$. This is mainly because they lack neuromuscular coordination, however visually impaired individuals do not lack neuromuscular co-ordination, have strong auditory reflexes and touch reflexes therefore it was necessary to evaluate the effectiveness of manual and electronic toothbrushes. This particular study aimed to assess and compare the effectiveness of manual tooth brushing and electronic tooth brushing reinforced with the use of touch perception (Braille) and audio aids. The effectiveness of these interventions was evaluated.

\section{Materials \& Methods}

This study was cross over clinical study which consisted of 2 phases of 1month duration each. 30 individuals within an age group of 18-35years from Pune Blind Man Association were selected for the study. All the individuals were completely blind. Verbally informed consent was taken from the authorities of Pune 
Blind Man Association. Approval for the study was granted by the M. A. Rangoonwala College of Dental Sciences and Research Centre.

\subsection{Inclusion criteria}

Subjects were completely blind individuals who were able to read Braille and did not have any hearing disability.

\subsection{Exclusion criteria}

Individuals who were unable to read Braille and had hearing disability. The subjects were asked to listen to audio aids and read Braille pamphlets which informed them about oral health care. The patients were taught to brush manually by Bass technique. The audio aids had a music pattern that would change for every surface. When the music pattern changed after every 15 seconds, a different tooth surface had to be brushed. The Braille pamphlets contained information about gum disease and brushing technique. This instruction sheet explained to patients that gum disease was swelling or soreness of the soft tissue around teeth, it was caused by bacteria in plaque (a sticky colourless film that sticks to teeth), plaque bacteria produce toxins that caused infection of gums called gingivitis, if plaque was not removed by brushing teeth it could build up and infect gums, teeth and supporting bone leading to more severe form of gum disease called periodontitis, if left untreated, it could lead to loss of bone and teeth. Instructions about brushing teeth included holding the toothbrush with the bristles at 45 degrees to the tooth surface, bristles were to be gently vibrated by moving the brush handle in a back and forth motion, strokes were to be repeated 20 times ( 3 teeth at a time).

According to a lottery system 15 patients were allocated electronic toothbrushes (Group A) and the other 15 (Group B) were allocated manual toothbrushes. At baseline, oral prophylaxis was completed. 4 weeks from baseline, the OHI (GREEN AND VERMILLION, 1960), GI (LOE AND SILNESS, 1963) and PI (SILNESS AND LOE, 1964) scores were recorded followed by statistical analysis.

A cross over was done at the end of 4 weeks. Group A now received manual toothbrushes Group B electronic toothbrushes. 4 weeks after the cross over the OHI, GI and PI scores were recorded and statistical analysis was done. At the end of the study, patient preference of manual and electronic toothbrushes was obtained. The patients were asked whether they preferred electronic or manual toothbrushes.

\section{Results}

For the following statistical analysis, Statistical Package for Social Sciences Version 20.0 for MS Windows software was used. The analysis for distribution of general characteristics of cases studied between the two study groups was done using the Chi-Square test. Values were (\% of cases). P-value $<0.05$ was considered statistically significant. The analysis for inter-group comparison of clinical parameters was done using the Mann-Whitney U test and for intra-group comparison of clinical parameters the Wilcoxon's signed rank test was used. Values were Mean \pm standard deviation. P-value $<0.05$ was considered to be statistically significant. For statistical analysis of distribution of preference for brushing technique between the two study groups the ChiSquare test was used. Values were n ( $\%$ of cases). P-values $<0.05$ was considered to be statistically significant. (S: statistically significant, NS: statistically non-significant).

The distribution of general characteristics of the cases studied between the two study groups(p-value> 0.05 ) did not differ significantly for age, sex, education, medical history and type of blindness

Table 1) The distribution of general characteristics of the cases studied between two study groups.

\begin{tabular}{|c|c|c|c|}
\hline Characteristics & $\begin{array}{l}\text { Electronic Tooth Brush }(\mathrm{n}=12) \\
\text { Group A }\end{array}$ & $\begin{array}{l}\text { Manual Tooth Brush }(n=14) \\
\text { Group B }\end{array}$ & P-value (Inter-group) \\
\hline \multicolumn{4}{|c|}{ Age group (years) } \\
\hline$\square \mathbf{2 0}$ & $2(16.7)$ & 4 (28.6) & 0.286 (NS) \\
\hline $20-24$ & $8(66.6)$ & $5(35.7)$ & \\
\hline$\square 25.0$ & $2(16.7)$ & $5(35.7)$ & \\
\hline \multicolumn{4}{|l|}{ Sex } \\
\hline Male & $8(66.7)$ & 11 (78.6) & 0.665 (NS) \\
\hline Female & $4(33.3)$ & $3(21.4)$ & \\
\hline \multicolumn{4}{|l|}{ Education } \\
\hline Up to SSC/HSC & $8(66.7)$ & $8(57.1)$ & 0.701 (NS) \\
\hline Under graduate & $4(33.3)$ & $6(42.9)$ & \\
\hline \multicolumn{4}{|l|}{ Medical history } \\
\hline Nil & $12(100.0)$ & $13(92.9)$ & 0.999 (NS) \\
\hline Positive & $\mathbf{0}$ & $1(7.1)$ & \\
\hline \multicolumn{4}{|l|}{ Blindness } \\
\hline Acquired & $4(33.3)$ & $10(71.4)$ & 0.113 (NS) \\
\hline Since Birth & $8(66.7)$ & 4 (28.6) & \\
\hline
\end{tabular}


Role Of Touch Perception And Audio Aids As Patient Education And Motivation Tools In Adjunct...

Values are $\mathrm{n}$ (\% of cases). P-values by Chi-Square test. P-value $<0.05$ is considered to be statistically significant. NS: Statistically Non-Significant.

In the intra-group comparison between electronic toothbrush group(Group A) and manual toothbrush group(Group B) the OHI,GI and PI scores improved significantly before and after the cross over(p-value $<0.05$ for all). In case of intergroup comparison, relatively higher improvement in OHI, GI and PI scores was evident in manual crossed over to electronic group but the differences did not reach statistical significance.

Table 2) The Intra-group and Inter-group comparison of clinical parameters studied.

\begin{tabular}{|c|c|c|c|}
\hline Parameters & $\begin{array}{l}\text { Electronic Tooth Brush } \\
(\mathrm{n}=12) \text { Group A }\end{array}$ & $\begin{array}{l}\text { Manual Tooth Brush } \\
(\mathrm{n}=14) \text { Group B }\end{array}$ & $\begin{array}{l}\text { P-value } \\
\text { (Inter-group) }\end{array}$ \\
\hline \multicolumn{4}{|l|}{ Oral hygiene index } \\
\hline Baseline & $1.93 \pm 0.88$ & $1.99 \pm 0.71$ & $0.756(\mathrm{NS})$ \\
\hline Post-usage-before cross over & $1.76 \pm 1.07$ & $1.72 \pm 0.77$ & 0.877 (NS) \\
\hline \% Change before cross over & $2.5 \%$ & $7.5 \%$ & 0.699 (NS) \\
\hline Post-usage-after cross over & $1.71 \pm 0.95$ & $1.57 \pm 0.70$ & 0.947 (NS) \\
\hline \% Change after cross over & $2.8 \%$ & $8.7 \%$ & 0.560 (NS) \\
\hline \multicolumn{4}{|l|}{ P-value (Intra-group) } \\
\hline Baseline v/s Post-usage before cross over & 0.289 (NS) & 0.593 (NS) & -- \\
\hline Baseline v/s Post-usage after cross over & 0.414 (NS) & 0.059 (NS) & -- \\
\hline \multicolumn{4}{|l|}{ Gingival index } \\
\hline Baseline & $1.34 \pm 0.33$ & $1.23 \pm 0.26$ & 0.468 (NS) \\
\hline Post-usage-before cross over & $0.87 \pm 0.46$ & $0.88 \pm 0.42$ & 0.857 (NS) \\
\hline \% Change before cross over & $35.1 \%$ & $29.8 \%$ & 0.719 (NS) \\
\hline Post-usage-after cross over & $0.79 \pm 0.53$ & $0.77 \pm 0.45$ & 0.338 (NS) \\
\hline$\%$ Change after cross over & $9.2 \%$ & $12.5 \%$ & 0.289 (NS) \\
\hline \multicolumn{4}{|l|}{ P-value (Intra-group) } \\
\hline Baseline v/s Post-usage before cross over & $0.008(\mathbf{S})$ & $0.003(\mathbf{S})$ & -- \\
\hline Baseline v/s Post-usage after cross over & $0.014(S)$ & $0.013(S)$ & -- \\
\hline \multicolumn{4}{|l|}{ Plaque index } \\
\hline Baseline & $1.23 \pm 0.32$ & $1.19 \pm 0.46$ & 0.470 (NS) \\
\hline Post-usage-before cross over & $0.98 \pm 0.36$ & $0.85 \pm 0.25$ & 0.236 (NS) \\
\hline \% Change before cross over & $19.6 \%$ & $26.2 \%$ & $0.571(\mathrm{NS})$ \\
\hline Post-usage-after cross over & $0.94 \pm 0.33$ & $0.79 \pm 0.19$ & 0.232 (NS) \\
\hline$\%$ Change after cross over & $4.1 \%$ & $7.1 \%$ & 0.367 (NS) \\
\hline \multicolumn{4}{|l|}{ P-value (Intra-group) } \\
\hline Baseline v/s Post-usage before cross over & $0.002(\mathrm{~S})$ & $0.008(S)$ & -- \\
\hline Baseline v/s Post-usage after cross over & $0.016(\mathrm{~S})$ & 0.028 (S) & -- \\
\hline
\end{tabular}

Values are Mean \pm standard Deviation. Inter-group comparisons done using Mann-Whitney U test. Intra-group comparisons done using Wilcoxon's signed rank test. P-value $<0.05$ is considered to be statistically significant. S: Statistically Significant, NS: Statistically Non-Significant.

Table 3) The distribution of preference for brushing technique between two study groups.

\begin{tabular}{|l|l|l|l|}
\hline Preference & $\begin{array}{l}\text { Electronic Tooth Brush (n=10) } \\
\text { Group A }\end{array}$ & $\begin{array}{l}\text { Manual Tooth Brush (n=12) } \\
\text { Group B }\end{array}$ & P-value (Inter-group) \\
\hline Manual preferred & $7(70.0)$ & $2(16.7)$ & $0.012(\mathrm{~S})$ \\
\hline Powered Preferred & $3(30.0)$ & $7(58.3)$ & \\
\hline Both Preferred & 0 & $3(25.0)$ & \\
\hline
\end{tabular}

Values are $\mathrm{n}$ (\% of cases). P-values by Chi-Square test. P-value $<0.05$ is considered to be statistically significant. NS: Statistically Non-Significant.

Significance (p-value $<0.05$ for all)

The visually impaired individuals preferred manual toothbrushes over electronic toothbrushes. The reason which was given by them at the end of the study was that they were more comfortable in applying the taught technique of brushing to the manual toothbrushes over electronic toothbrushes. Some complained of minor injury to the gingival with the electronic toothbrush bristle. Also the lack of awareness of electronic toothbrush limits their use.

Therefore, manual toothbrushes along with audio aids and Braille instruction sheet which provides them constant reinforcement of oral health care prove to be a viable, cheaper and readily available alternative for ensuring optimum periodontal health.

Also the audio aids can be used as excellent patient education and motivation tools for future oral health care programs in patients who do not lack visual impairment. 
- Manual toothbrushes were preferred over electronic toothbrushes.

- Braille and audio aids reinforced patients to maintain the oral hygiene.

- All the participants seemed enthusiastic enough for incorporation of the patient education and motivation aids in daily maintenance of oral hygiene.

\section{Discussion}

The study was conducted to compare the efficacy of manual and electronic toothbrushes reinforced with audio instructions and Braille instruction sheet in visually impaired individuals. In this study age, sex, education and medical history did not differ significantly between the two study groups and hence did not have an effect on their oral hygiene status.

The inter-group and intra-group comparison between the 2 groups (Group A) and (Group B) suggests that both the manual and electronic toothbrushes were equally effective.

OHI, GI and PI values improved more in case of the manual group crossed over to electronic but were statistically insignificant. This may be due to over enthusiasm of the individuals to use the newly introduced electronic toothbrushes (novelty effect).

The oral health of visually impaired people can be poor, since they are not in a position to detect and recognize early oral disease and may be unable to take immediate action unless informed of the situation ${ }^{6}$.The removal of plaque and debris from the teeth is a skill that can be mastered only when an individual has the dexterity to manipulate the toothbrush and understands the objectives of these activities ${ }^{13}$. Adequate oral hygiene instructions may have a positive impact on individuals' oral hygiene habits and periodontal status, thereby improving their self-esteem ${ }^{7,8}$.

Although manual toothbrushes need manual dexterity in maintaining oral hygiene, tactile senses of the visually impaired individuals when capped along with the use of audio aids bring about results comparable to electronic toothbrushes. Many studies support the concept that powered tooth brushing can provide additional clinical benefit in plaque removal and inflammation reduction when subjects receive proper instructions and training on the use of the electronic toothbrushes. ${ }^{14,15}$

The Hawthorne effect (Heasmanet $\mathrm{al}^{16}$, Ainamo et $\mathrm{al}^{14}$ ) which results from change in behaviour of a subject who anticipated involvement in clinical study could be a confounding source of variability in a cross over trial. These cause differences between the first and second part of the study. In our study the anticipation of an upcoming appointment may have prompted the participants to perform better tooth brushing.

The audio aids and Braille instruction sheet given to the patients were excellent patient education and motivation tools. These were used by patients to refer back to the oral hygiene instructions whenever required. Bratelet $\mathrm{al}^{17}$ had reported that the reduced positive effect over time in maintaining oral hygiene shows that reinstruction is more important in a prophylactic program than to operate with different toothbrushes.

The visually impaired individuals preferred manual toothbrushes over powered toothbrushes because they were more comfortable in applying the taught technique of brushing in manual toothbrushes than in electronic toothbrushes. However, a more detailed study comprising of a larger sample size, including a longer duration of usage along with newer generations of powered toothbrushes will help in better understanding of the benefits of powered toothbrushes in visually disabled individuals with sufficient manual dexterity but lack of vision. Hence, manual toothbrushes along with audio aids and Braille instruction sheet which provide them constant reinforcement of oral health care prove to be a viable, cheaper and readily available alternative for ensuring optimum oral health in visually impaired individuals ${ }^{18}$.

\section{Conclusion}

Tactile sensation (use of Braille) and audio aids reinforced the patients to maintain their oral hygiene. However there was no difference between manual and electronic toothbrushes.

\section{Acknowledgement}

We would like to thank Blind Man Association, Pune for allowing the study to be done on their students.

\section{Refernces}

[1]. Socransky S, Haffajee A (1992)The bacterial etiology of destructive periodontal disease:current concepts.J Periodontol 63:322-331

[2]. Axelsson P, Nyström B, Lindhe J (2004) The long-term effect of a plaque control program on tooth mortality, caries and periodontal disease in adults. Results after 30 years of maintenance. J ClinPeriodontol 31:749-757

[3]. Greeley CB, Goldstein PA, Forrester DJ. (1976). Oral manifestations in a group of blind students. ASDC J Dent Child, 43: 39-41.

[4]. Anaise Z. J. (1979). Periodontal disease and oral hygiene in a group of blind and sighted Israeli teenagers (14-17 years age). Comm Dent Oral Epidemiol, 7, 353-6.

[5]. Edwards DM, Merry AJ. Disability part 2: access to dental services for disabled people. A questionnaire survey of dental practices in Merseyside. Br Dent J. 2002; 13(5):253-255.

[6]. Schembri A, Fiske J. The implications of visual impairment in an elderly population in recognizing oral disease and maintaining oral health. Spec Care Dent 2001; 21: 222-226. 
[7]. Ajwani S, Ainamo A. (2001), periodontal conditions among the elderly: Five-year longitudinal study. Special Care in Dentistry. 21:45-51.

[8]. Schnuth M.L., (1977), Dental health education for the blind. Dental Hygiene. 51:499-501.

[9]. Full CA, Kerber PE, Boender P, Schneberger N. Oral health maintenance of the institutionalized handicapped child. J Am Dent Assoc 1977; 94:111-3.

[10]. Bozkurt FY, Fentoglu O, Yetkin Z. The comparison of various oral hygiene strategies in neuromuscularly disabled individuals. J Contemp Dent Pract. 2004; 5:23-31.

[11]. Hoover JN, Singer D. Toothbrushes: Manual and electric. J Can Dent Assoc. 1994; 60:880-4.

[12]. Ashley P. Toothbrushing: Why, when and how? Dent Update. 2001; 28:36-40.

[13]. Pinkham JR. Oral hygiene in children: relationship to age and brushing time. J Prev Dent 1975; 2:28-3.

[14]. Ainamo J, Xie Q, Ainamo A, Kallio P. Assessment of the effect of an oscillating/rotating electric toothbrush on oral health. A 12month longitudinal study. J ClinPeriodontol. 1997; 24:28-33.

[15]. van der Weijden GA, Timmerman MF, Reijerse E, et al. The long-term effect of an oscillating/rotating electric toothbrush on gingivitis. An 8-month clinical study. J ClinPeriodontol 1994; 21, 139-145.

[16]. Heasman PA, McCraken GI. Powered toothbrushes: A review of clinical trials. J Clin Periodontol.1999; 26:407-20.

[17]. Bratel $\mathbf{J}^{1}$, Berggren U. Long-term oral effects of manual or electric toothbrushes used by mentally handicapped adults. ClinPrev Dent. 1991 Jul-Aug; 13(4):5-7.

[18]. Goyal S, Thomas BS, Bhat KM, Bhat GS. Manual toothbrushing reinforced with audiovisual instruction versus powered toothbrushing among institutionalized mentally challenged subjects - A randomized cross-over clinical trial. Med Oral Patol Oral Cir Bucal. 2011; 16:e359-64.

[19]. John C. Greene, Jack R. Vermillion. The oral hygiene index, a method for classifying oral hygiene status. The journal of American Dental Association 1960; 61, 172-179.

[20]. Loe H, Silness J. Periodontal disease in pregnancy. I. Prevalence and severity. ActaOdontol Scand.1963; $21: 533-51$.

[21]. Silness J, Löe H. Periodontal disease in pregnancy. II. Correlation between oral hygiene and periodontal condition. ActaOdontol Scand. 1964; 22: 121-135.

[22]. Mahantesha T, Nara A, Kumari PR, Halemani PK, Buddiga V, Mythri S. A comparative evaluation of oral hygiene using Braille and audio instructions among institutionalized visuallyimpaired children aged between 6 years and 20 years: A 3-month follow-up study. J IntSocPrev Community Dent. 2015 Dec; 5(Suppl 2):S129-32. 